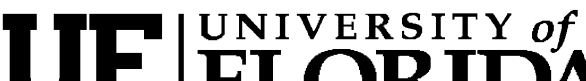 FLORIDA \\ IFAS Extension
}

\section{Dissolved Organic Matter in Wetlands ${ }^{1}$}

\author{
Alan L. Wright and K.R. Reddy ${ }^{2}$

\section{Introduction}

Dissolved organic matter (DOM) consists of soluble organic materials derived from the partial decomposition of organic materials, including soil organic matter, plant residues, and soluble particles released by living organisms, including bacteria, algae, and plants. Dissolved organic matter is easily identified as it is responsible for the dark tea color typical of many of Florida's surface waters. All soils have organic matter dissolved in soil solution or in floodwater, but its concentration is generally greater in wetland and aquatic ecosystems than agricultural soils. Dissolved organic matter is significant in many respects due to the role it plays in nutrient sequestration and supply and as it is an available carbon source for microorganisms. The objective of this document is to describe the importance of DOM and its role in regulating nutrients in terrestrial and aquatic ecosystems.

\section{Ecological Significance}

The ecological significance of DOM is not very well understood and has not been clearly defined. This is mainly due to lack of a clear understanding of DOM composition and its cycling, biodegradability,

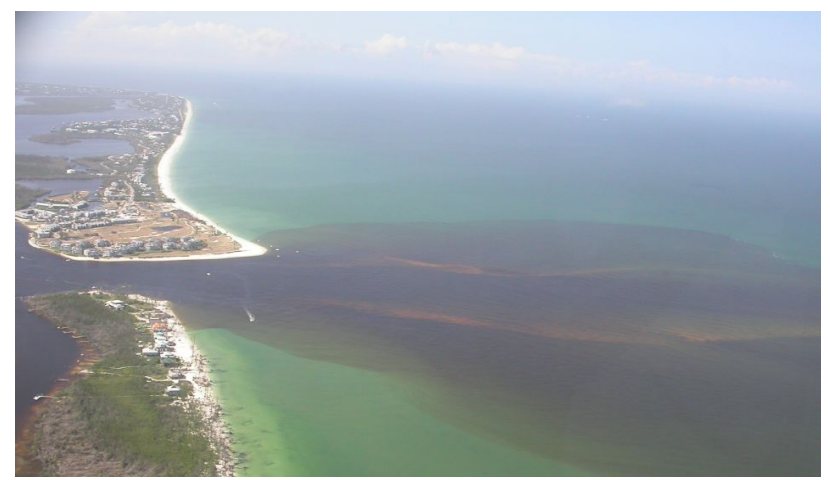

Figure 1.

and relationships with nutrients. The DOM represents a broad spectrum of organic compounds of varying degradability or recalcitrance, and consists of both labile (available) and non-labile (recalcitrant) organic matter (the major fraction). Phenol oxidase, an enzyme produced by microorganisms and fungi, is responsible for converting many of the recalcitrant components of DOM into labile carbon, which makes the carbon more utilizable by other microorganisms. The turnover of highly labile, energy-rich organic substrates of DOM may approach a rate of 5-10 times per day. Despite the fact that recalcitrant DOM is slow to mineralize, these pools represent a major portion of the organic matter processed by microorganisms in wetlands.

1. This document is SL 294, one of a series of the Soil and Water Science Department, Florida Cooperative Extension Service, Institute of Food and Agricultural Sciences, University of Florida. Original publication date June 2009. Visit the EDIS Web site at http://edis.ifas.ufl.edu.

2. Alan L. Wright, assistant professor, Department of Soil and Water Science, Everglades Research and Education Center (REC)--Belle Glade FL; K.R. Reddy, professor, Department of Soil and Water Science; Florida Cooperative Extension Service, Institute of Food and Agricultural Sciences, University of Florida, Gainesville, FL 32611.

The Institute of Food and Agricultural Sciences (IFAS) is an Equal Opportunity Institution authorized to provide research, educational information and other services only to individuals and institutions that function with non-discrimination with respect to race, creed, color, religion, age, disability, sex, sexual orientation, marital status, national origin, political opinions or affiliations. U.S. Department of Agriculture, Cooperative Extension Service, University of Florida, IFAS, Florida A. \& M. University Cooperative Extension Program, and Boards of County Commissioners Cooperating. Millie Ferrer, Interim Dean. 
Water draining from wetlands often contains high concentrations of darkly colored DOM, which carries not only carbon, but also nitrogen, phosphorus, and metals. Since DOM represents an important mechanism for nutrient mobility, it plays a major role in determining the balance and accumulation of nitrogen, phosphorus, and perhaps even carbon over the long period of soil development. Also, because DOM is a powerful agent for the binding of metals, it plays an important role in regulating metal toxicity and mobility, e.g. mercury. It also functions to control the $\mathrm{pH}$ of many wetland waters which in turn influences the availability of toxic metals.

Dissolved organic matter is of interest to ecologists because it affects the physical, chemical, and biological properties of freshwater systems. Through attenuation of solar radiation, DOM provides ultraviolet radiation protection for algae and plankton. Reductions in DOM concentrations can increase water transparency and increase sunlight penetration, encouraging growth of plants and aquatic organisms. Phytoplankton release large portions of their photosynthate to the open waters as extracellular DOM. The DOM can also support bacterial secondary production, influence the availability of some forms of phosphorus to phytoplankton, and alter sediment accretion rates in wetlands.

\section{DOM and Water Color}

Allochthonous (from outside sources) DOM can enter aquatic ecosystems through precipitation, leaching, and decomposition. Highly productive wetlands generate massive amounts of organic matter that enter other aquatic systems primarily in dissolved form. This tea-colored DOM is composed of fulvic and humic acids, products of the degradation of lignin and cellulose. Thus, the concentration of DOM in lakes and rivers can provide a useful index of the influence of the surrounding watershed.

\section{Input and Export}

Wetlands around the world are experiencing disturbances such as drainage, eutrophication, and problems with heavy metal toxicity which either influence or are influenced by DOM. In the Florida Everglades, all three disturbances are important.
Agricultural nutrients have been draining from the Everglades Agricultural Area into the northern Everglades for decades, causing enrichment of certain areas. There is a growing concern about the transport of nutrients to Florida Bay (Reddy et al. 1999). Mercury toxicity is a major problem in many wetlands around the world, and it is largely transported by DOM (Strober et al. 1995).

Landscape patterns, such as drainage, slope, water residence time, and the percentage of the watershed covered by wetlands can strongly influence DOM. Wetlands and wetland soils are often the source of DOM input to lakes and streams even though they may occupy only a small percentage of the catchment area. It is not fully understood how proximity and positioning of landscape units such as wetlands influence the export and resulting concentrations of watershed inputs. Our understanding of the processes that control the concentration and export of DOM and the elements carried by it in wetlands is limited.

The concentrations of DOM in waters are a product of inputs (production of new soluble organic matter and imports), exports (microbial decomposition and solar mineralization), and exchanges with the solid organic matter by adsorption and desorption. The inputs of new DOM are substantially increased by plant productivity associated with phosphorus enrichment, as demonstrated in the Everglades. This increase was not only associated with increased productivity but by a shift in vegetation species from sawgrass to cattail, which produces more DOM in newly senesced litter. The concentrations of DOM are also influenced by outputs due to microbial decomposition and mineralization caused by solar radiation. The rate of microbial decomposition seems very slow compared to other processes of input, hydrologic transport, and adsorption. In fact, natural levels of solar radiation in sunlight near the water surface can potentially mineralize dissolved organic nutrients much faster than microorganisms. Solar radiation degrades the humic fraction, which is resistant to decay, and perhaps inhibitory, to microbial degradation. In terms of the eutrophication of the Everglades and other wetlands, it might be considered desirable if dissolved organic nutrients were not mineralized and 
simply flowed through the system. The export of DOM in water from the various areas of the Everglades has important implications for downstream environments. Not only is most nitrogen carried in DOM but also mercury is transported while bound to DOM (Strober et al. 1995). Sorption and desorption of DOM from peat soils act as a buffer and strongly regulates DOM concentrations in waters. In other wetlands, hydrologic flowthrough, the concentration of DOM in water, the adsorption properties of peat, the solar radiation reaching the water column, and plant productivity influence the relative importance of DOM cycling.

The flooding of drained soils results in a flush of DOM from soil to the overlying water column. Organic matter decomposition under these conditions is typically slower and results in solubilization of organic matter and accumulation of dissolved organic compounds. Thus, flux of DOM from soil to overlying water column is rapid during the first few months of flooding and decreases with time. In surface waters, DOM of algal and macrophyte origin can be an important contributor to the total DOM pool. The relative importance of these two sources (algae and macrophytes) depends on water depth, nutrient status, and physico-chemical environment in the water column. The DOM produced from these sources consists of low-molecular weight compounds, is biologically labile, and is readily used as an energy source by microorganisms.

During periods of drought or low water levels, organic matter decomposition rates will increase. Exposed areas in wetlands then exhibit enhanced decomposition of the organic soils and release metals and nutrients contained within organic matter as well as increase DOM concentrations. A shift from anaerobic decomposition to aerobic decomposition occurs after drainage. The ultimate fates of these mineralized components will depend on vegetation and environmental conditions. Some nutrients can be taken up by wetland vegetation and have minimal effect on surface waters. However, nutrients and metals in wetland floodwater are mobile and may eventually be exported to rivers and lakes, thereby increasing concentrations and potential for stimulation of microbial activity. This may lead to undesirable consequences such as eutrophication, algal blooms, and fish kills.

\section{Summary}

The role of DOM in terrestrial and aquatic systems is an important one as this material is supplied by soil, plants, and aquatic algae and microorganisms. As such, it is often rich in nutrients. Being soluble, DOM is a significant means by which nutrients are transported across landscapes.

Dissolved organic matter also acts to sequester toxic metals from the environment and prevent them from harming biological organisms. However, decomposition of DOM by microorganisms can serve to release metals and nutrients to the environment. The colored surface waters in Florida are due in part to the presence of DOM, which tends to regulate sunlight penetration into the water column and thus influences nutrients, phytoplankton, and other organisms. The wide-reaching influence of DOM in aquatic systems still, however, is not entirely understood and needs further study.

\section{For more information}

Reddy, K.R., R.H. Kadlec, E. Flaig, and P.M. Gale. 1999. Phosphorus retention in streams and wetlands: a review. Crit. Rev. Environ. Sci. Technol. 29:83-146.

Strober, Q.J., R.D. Jones, and D.J. Scheidt. 1995. Ultra-trace level mercury in the placeEverglades ecosystem: a multi media canal pilot study. Water Air Soil Pollut. 80:991-1001. 